\title{
EDUCAÇÃO NO SEMIÁRIDO BRASILEIRO: \\ CONTEXTUALIZANDO A EDUCAÇÃO AMBIENTAL COMO ESTRATÉGIA DE DESENVOLVIMENTO SUSTENTÁVEL
}

\author{
Marta Maria Aguiar Sisnando Silva ${ }^{1}$ \\ Patrícia Verônica Pinheiro Sales Lima² \\ Ahmad Saeed Khan ${ }^{3}$ \\ Leonardo Andrade Rocha ${ }^{4}$
}

Resumo: O objetivo do artigo é discutir a Educação Ambiental nas escolas do Semiárido brasileiro, considerando a sua importância como estratégia de desenvolvimento sustentável local. Para tanto é feita uma análise da educação contextualizada no Semiárido e em seguida apresenta-se uma reflexão sobre a atuação dos municípios nesse processo. A Educação Ambiental não se encontra institucionalizada no Semiárido. De um modo geral existe um ambiente desfavorável a sua implementação e o governo municipal é omisso no que se refere à adoção de instrumentos de gestão da educação que poderiam agir como catalisadores de processos de transformação de comportamentos para enfrentar com os problemas socioeconômicos e ambientais da região.

Palavras-chave: Semiárido; Desenvolvimento Regional; Gestão da Educação.

${ }^{1}$ Banco do Nordeste/Universidade Coorporativa. Email: marta_aguiar8@hotmail.com

2 Universidade Federal do Ceará. E-mail: pvpslima@gmail.com

${ }^{3}$ Universidade Federal do Ceará. Email: saeed@ufc.br

${ }^{4}$ Universidade Federal do Semiárido. Email: leonardoandrocha@yahoo.com.br 


\section{Introdução}

O Semiárido brasileiro costuma ser descrito como a região mais frágil e vulnerável do Brasil (VIANA; RODRIGUES, 1999). Os problemas na área incluem desigualdade social, concentração de terras, pobreza, baixos níveis de escolaridade, desmatamentos, perda da biodiversidade e da fertilidade do solo e processos de desertificação (BUAINAIN; GARCIA,2013). As condições climáticas e a ação antrópica são apontadas como fatores determinantes das condições socioeconômicos e ambientais locais (ARAÚJO; SOUSA, 2011). De acordo com Andrade e Queiroz (2009), a população do Semiárido brasileiro, principalmente a que vive na zona rural, apresenta os mais elevados índices de analfabetismo do país, retrato do quadro de exclusão social que castiga essa região e resultado de um modelo de educação, especialmente no âmbito do ensino formal, que desvaloriza o espaço rural e as relações sociais ali estabelecidas, conduzindo a uma baixa autoestima e construindo culturalmente o êxodo rural e a descrença da viabilidade de se poder desfrutar de uma vida digna no Semiárido.

Diante desse cenário, além das políticas públicas, as mudanças de comportamento passam a ser fortes aliadas no combate à problemática regional. Mudanças de comportamento, por sua vez, requerem a sensibilização da população para identificar o seu papel como agente transformador do ambiente em que vive. Na concepção de Hungerford e Volk (1990), isso ocorre por meio de uma Educação Ambiental.

A Educação Ambiental está inserida em um processo de contextualização da educação, o qual seguindo as diretrizes do artigo 14 da Carta da Terra, busca: "integrar, na educação formal e na aprendizagem ao longo da vida, os conhecimentos, valores e habilidades necessárias para um modo de vida sustentável". No entanto, assim como as políticas públicas direcionadas ao combate às secas recorrentes verificadas na região, as políticas educacionais centraram-se, por muitos anos e de forma equivocada, na importação de experiências externas nem sempre adaptáveis à realidade da região. Como consequência, as escolas atuantes no Semiárido apresentam uma estrutura curricular pouco integrada a uma educação contextualizada e com expectativas reduzidas no sentido de contribuir para uma mudança do cenário socioeconômico e ambiental local.

A educação contextualizada tem papel fundamental no desenvolvimento local. Autores como Paton e Jonhston (2001) e Lima e Khan (2011) colocam que as abordagens tradicionais da educação formal têm se mostrado pouco eficazes quanto ao aumento da participação da população nas estratégias voltadas para 0 desenvolvimento sustentável. Os autores ressaltam a importância de um ensino contextualizado, de maneira a ter significado e sentido para as pessoas, mostrando evidências quanto à sua aplicação na vida cotidiana e ao respeito à identidade, cultura e práticas ao meio ambiente onde esses sujeitos estão inseridos. Braga (2004) argumenta que a educação contextualizada no Semiárido é uma proposta de educação ancorada na 
realidade e na prática dos moradores, levando em conta potencialidades socioculturais, econômicas e ambientais.

Destarte os diferentes e diversos processos educativos identificados na região ${ }^{5}$, a maioria associados às medidas de convivência com a seca e difundidos por redes de associações e organizações não governamentais, o foco deste artigo é a educação formal, mais especificamente a inserção da Educação Ambiental nos currículos das escolas municipais do Semiárido. O objetivo é discutir a Educação Ambiental nas escolas do Semiárido brasileiro, considerando a sua importância como estratégia de desenvolvimento sustentável local e na perspectiva de ruptura de uma estrutura curricular que reproduz e perpetua a disseminação de informações que não representam a realidade do Semiárido e não contribuem para criar um ambiente de convivência com as condições locais (Moura, 2003; RESAB, 2006).

$\mathrm{O}$ artigo encontra-se estruturado em quatro seções. Após essa introdução, a segunda seção discute sobre a importância educação contextualizada no Semiárido e uma breve descrição da trajetória da Educação Ambiental no Semiárido. Na terceira seção é feita uma análise sobre a inserção da Educação Ambiental nas escolas da região e a atuação dos municípios nesse processo. Por fim, na última seção, são colocadas as considerações finais.

\section{Educação contextualizada, Educação Ambiental e a convivência com o Semiárido}

A educação contextualizada consiste numa proposta de educação ancorada na realidade e nas práticas, culturas e costumes dos povos, com metodologias, conteúdos, currículos, educadores e educadoras, didáticas e estruturas apropriadas à região, considerando suas potencialidades socioculturais, econômicas e ambientais, ou seja, uma transformação políticopedagógica (ANDRADE; QUEIROZ, 2009). É uma concepção a ser inserida em qualquer estratégia de desenvolvimento local, pois pode criar competências para solucionar problemas específicos. No entanto,

\begin{abstract}
desconsidera-se que a contextualização é um dos processos de formação das competências necessárias ao trabalho na sociedade globalizada e à inserção no mundo tecnológico. Ainda que esse mundo seja muito diferenciado em relação ao início do século $X X$, quando foram produzidas as principais teorias da eficiência social, permanece a finalidade de submeter a educação ao mundo produtivo. Prevalece a restrição do processo educativo à formação para o trabalho e para a inserção social, desconsiderando sua relação com o processo de formação cultural mais ampla, capaz de conceber o mundo como possível de ser transformado em direção a relações sociais menos excludentes (LOPES, 2002, p.395).
\end{abstract}

\footnotetext{
${ }^{5}$ A disseminação de cisternas de placa, sistemas agrossilvopastoris, quintais produtivos, por exemplo, adotam práticas pedagógicas perfeitamente inseridas na educação contextualizada.
}

revista brasileira educação ambiental 
A argumentação de Lopes (2002) se adequa à realidade vivenciada no Semiárido brasileiro. Durante anos buscou-se implementar na região um modelo de desenvolvimento baseado em experiências que obtiveram êxito em outras regiões do país, mas que se mostraram incapazes de atender às demandas locais. No entanto, desde a década de 1980, essa postura vem sendo modificada. O Semiárido ganhou um olhar diferenciado. Novos atores, destacando-se a importância da criação da Articulação do Semiárido (ASA) em 1993, vêm empreendendo ações junto aos órgãos governamentais e à sociedade civil no sentido de adoção de práticas de desenvolvimento centradas na sustentabilidade econômica, social, ambiental, política e cultural (FARIAS e PINHEIRO, 2012). Essas ações são entendidas e difundidas como práticas de convivência com o Semiárido.

Para Farias e Pinheiro (2012), as políticas públicas voltadas para a convivência com o Semiárido, englobando o diálogo entre os diversos atores envolvidos no processo de desenvolvimento dessa região, passam pela necessidade de mudanças também no processo de educação, dado que as práticas de convivência com o Semiárido envolvem estratégias de mitigação e adaptação às mudanças climáticas e demandam a sensibilização e a capacitação da população para as novas realidades econômicas, naturais e sociais que se desenvolvem no âmbito das ações em curso. Dessa forma, se faz necessária a implementação de um programa massivo de investimento em educação integral de todas as crianças e jovens (NOBRE, 2011), com enfoque em uma educação contextualizada.

A Educação Contextualizada no Semiárido tem como uma de suas bases de sustentação a Lei de Diretrizes e Bases da Educação Nacional (LDB 9394/96), a qual favoreceu a atuação de Organizações Não-Governamentais (ONG's) e outros agentes educadores externos à escola (SOUZA, 2013). Nesse novo ambiente, a Rede de Educação do Semiárido (RESAB), criada em outubro de 2000, exerce um papel relevante de articulação de educadores e instituições governamentais e da sociedade civil que atuam na área de educação. O trabalho da rede envolve a construção e implementação de políticas educacionais inclusivas e contextualizadas, vinculando os currículos e as metodologias de ensino-aprendizagem às problemáticas específicas da região e estimulando os educandos a atuarem como sujeitos e protagonistas de seu aprendizado, participando ativamente e exercitando seu potencial criativo na construção e reconstrução do conhecimento que perpassa suas experiências de vida numa troca constante de saberes entre esses atores (professores, alunos, sociedade como um todo), dando sentido e concretude ao aprendizado, que precisa ir além do conceitual - ler, escrever, contar e repetir o que ouviu.

Silva, Rodriguez e Meireles (2011) citam como principais problemas do Semiárido brasileiro a segurança alimentar, o colapso ambiental e o desenraizamento da identidade local e regional. Como principais eixos de ação para solucionar tais problemas, os autores apontam o papel da diversidade, a necessidade de convivência com a realidade do Semiárido e a diversificação das atividades produtivas e ressaltam que há necessidade de se articular as 
concepções sobre desenvolvimento sustentável, planejamento ambiental, planejamento territorial, gestão de recursos hídricos e o manejo de bacias hidrográficas, sendo este um desafio fundamental para a avaliação científica da questão.

A convivência consiste em (re)significar o pensamento e ampliar o alcance da contextualização em sintonia com as potencialidades, limites e necessidades, com base nas visões de mundo e nos planos para um futuro melhor. Isso se dá por meio do estabelecimento de relações harmoniosas entre o homem e a natureza, visando à melhoria da qualidade de vida e depende de políticas coerentes com o potencial da região, cultura e saberes locais (FARIAS; PINHEIRO, 2012).

A convivência com o Semiárido passa por uma mudança de cultura que envolve a promoção do desenvolvimento sustentável dessa região, visando à melhoria da qualidade de vida e o resgate da cidadania por meio de iniciativas socioeconômicas e tecnológicas apropriadas e compatíveis com a preservação e renovação dos recursos naturais, originando um novo paradigma civilizatório que articula diversas dimensões do desenvolvimento (SILVA, 2007):

- Social - acesso a bens e serviços fundamentais como educação, saúde, moradia, saneamento, assistência social e previdenciária, lazer, etc, que se constituem a base para superação da pobreza, articulados com mudanças na forma de dominação sociais, étnicas, de gênero e de geração;

- Cultural - Reconstrução dos saberes locais como forma de convivência por meio da educação contextualizada;

- Econômica - Geração de trabalho e renda por meio de alternativas de produção includentes e apropriadas às potencialidades e limitações do Semiárido, além da democratização do acesso aos meios de produção;

- Ambiental - Recuperação e conservação dos recursos naturais por meio de tecnologias e práticas de manejo sustentável;

- Política - Fortalecimento da sociedade civil e da participação do cidadão na formulação das políticas públicas adequadas à região.

Considerando-se a proposta da educação contextualizada, é factível assumir o seu papel catalisador em todas as dimensões colocadas. Dentro da perspectiva de mudança de paradigma de uma região "sem solução" para uma trajetória de desenvolvimento baseada na convivência com a realidade do Semiárido, considerando suas peculiaridades físicas, climatológicas, culturais, políticas e sociais, faz-se mister a integração dos saberes populares, científicos e acadêmicos bem como das instituições da sociedade civil e do setor público, de acordo com práticas contextualizadas com a realidade desse espaço e 
norteadas nos princípios do crescimento econômico com justiça social, proteção e manutenção dos recursos naturais (FARIAS PINHEIRO, 2012).

A educação contextualizada no Semiárido tem se manifestado de forma concreta em algumas práticas de convivência disseminadas entre a população. Muitas iniciativas dialogam com a temática. É o caso do Programa 1 Milhão de Cisternas (P1MC), Programa de Formação e Mobilização Social para a Convivência com o Semiárido - Uma Terra e Duas Águas (P1+2), Projeto Dom Hélder Câmara. Destacam-se, ainda, vivências adquiridas em experiências como: práticas agroecológicas, sistemas agrossilvopastoris, produção de mel, quintais produtivos, mandalas e bancos de sementes; as quais agem como processos emancipatórios de expansão da capacidade criadora da população local (SILVA, 2007). As iniciativas citadas, e outras tantas, são o resultado do protagonismo de agentes que atuam no Semiárido com o propósito comum de promover o desenvolvimento local em bases sustentáveis. O Quadro 1 apresenta atores relevantes nesse processo, cuja ação tem favorecido, direta e indiretamente, a difusão da educação contextualizada na região:

Quadro 1: Agentes facilitadores da educação contextualizada no Semiárido brasileiro.

\begin{tabular}{|c|c|c|}
\hline Agente difusor & Atuação & Fonte \\
\hline $\begin{array}{l}\text { Rede de Educação } \\
\text { do Semiárido } \\
\text { Brasileiro (RESAB) }\end{array}$ & $\begin{array}{l}\text { intuito de elaborar propostas de políticas } \\
\text { públicas no campo educacional e } \\
\text { desenvolver ações que possam contribuir } \\
\text { com a melhoria da qualidade do ensino e do } \\
\text { sistema educacional PÚBLICO do semi-árido } \\
\text { brasileiro }\end{array}$ & http://resabnacional.blogspot.com \\
\hline $\begin{array}{l}\text { ASA - Articulação } \\
\text { Semiárido Brasileiro }\end{array}$ & $\begin{array}{l}\text { gestão e no desenvolvimento de políticas de } \\
\text { convivência com a região semiárida. Sua } \\
\text { missão é fortalecer a sociedade civil na } \\
\text { construção de processos participativos para } \\
\text { o desenvolvimento sustentável e a } \\
\text { convivência com o Semiárido referenciados } \\
\text { em valores culturais e de justiça social. }\end{array}$ & http://www.asabrasil.org.br \\
\hline $\begin{array}{l}\text { Serta - Serviço de } \\
\text { Tecnologia } \\
\text { Alternativa }\end{array}$ & $\begin{array}{l}\text { formar jovens, educadores/as e } \\
\text { produtores/as familiares por meio da } \\
\text { Proposta Educacional de Apoio ao } \\
\text { Desenvolvimento Sustentável (Peads), } \\
\text { metodologia que trabalha com sistemas } \\
\text { formais e não-formais de educação na } \\
\text { perspectiva de mobilização social e } \\
\text { construção de bases tecnológicas e sociais } \\
\text { que o desenvolvimento sustentável requer. }\end{array}$ & http://www.serta.org.br \\
\hline Caritas & $\begin{array}{l}\text { mobilização e organização comunitária; } \\
\text { formação técnica e política para o } \\
\text { desenvolvimento local sustentável; } \\
\text { implementação de obras hídricas (cisternas, } \\
\text { pequenas barragens, perfuração de poços) e } \\
\text { de projetos produtivos (criação de pequenos } \\
\text { animais, lavouras coletivas, hortas } \\
\text { medicinais, entre outros). } \\
\text { A entidade atua também na formação de } \\
\text { educadores/as e comunidades para a } \\
\text { educação contextualizada à região, } \\
\text { valorizando os saberes e as culturas locais. }\end{array}$ & http://caritas.org.br/ \\
\hline
\end{tabular}


...continuação.

\begin{tabular}{|c|c|c|}
\hline Agente difusor & Atuação & Fonte \\
\hline $\begin{array}{l}\text { RECASA - Rede } \\
\text { de Educação } \\
\text { Contextualizada } \\
\text { para o Agreste e } \\
\text { Semiarido }\end{array}$ & $\begin{array}{l}\text { ações são voltadas para } \\
\text { implementações de propostas que } \\
\text { fortaleça a educação para convivência e } \\
\text { sustentabilidade local. Objetivos } \\
\text { Fortalecer as ações coletivas de } \\
\text { implantação da Proposta de educação } \\
\text { para convivência com o semi-árido nos } \\
\text { municípios abrangentes; Desenvolver } \\
\text { processo de formação continuada em } \\
\text { educação contextualizada para os } \\
\text { educadores envolvidos; Mobilizar a } \\
\text { sociedade em geral para tornar a } \\
\text { proposta de educação para convivência } \\
\text { com o semi-árido em política pública. } \\
\text { Buscar assessoria para elaboração dos } \\
\text { PME'S com enfoque na Educação } \\
\text { Contextualizada. }\end{array}$ & http://recasa.blogspot.com/ \\
\hline $\begin{array}{l}\text { Rede de Educação } \\
\text { Ambiental da } \\
\text { Paraíba }\end{array}$ & $\begin{array}{l}\text { articulação de entidades governamentais ou } \\
\text { não, educadores, ambientalistas e outros } \\
\text { interessados na temática da educação } \\
\text { ambiental na Paraíba, constituída com o } \\
\text { objetivo de difundir informações, trocar } \\
\text { experiências e construir estratégias de } \\
\text { Educação Ambiental, para promover o } \\
\text { compromisso social frente ao desafio da } \\
\text { preservação do meio ambiente, em todas as } \\
\text { suas dimensões. }\end{array}$ & http://www.prac.ufpb.br/reapb/ \\
\hline
\end{tabular}

Fonte: Elaboração própria

Apesar da mobilização percebida nas últimas décadas, a inserção da educação contextualizada no ensino formal tem se manifestado de forma lenta. Para Baptista e Campos (2013), a percepção do papel da educação contextualizada como vetor de desenvolvimento do Semiárido vem provocando modificações graduais na educação formal, assim como aconteceu com a extensão rural. Para os autores já são percebidas mudanças na alfabetização de adultos e a existência de material didático, livros textos e materiais de estudo para crianças e professores, em substituição aos livros importados de outras regiões do país, especialmente Sul e Sudeste. No entanto, a concretização da educação contextualizada nos espaços escolares do Semiárido ainda está longe de ser alcançada, especialmente se analisada na perspectiva da Educação Ambiental (EA), tão importante para a convivência da população com o Semiárido, principalmente a população rural (BARBOSA; SANTOS, 2015).

A EA está presente na pauta de debates internacionais sobre meio ambiente desde a década de 1970, quando, durante a Conferência de Estocolmo ocorrida em 1973, foi reconhecida a sua importância para a solução dos problemas ambientais mundiais. Três eventos podem ser destacados como determinantes para a difução das ideias e princípios embutidos na Educação Ambiental: a Primeira Conferência Intergovernamental sobre Educação 
Ambiental - Conferência de Tbilisi - promovida pela Organização das Nações Unidas para a Educação, a Ciência e a Cultura (UNESCO) em 1977, a Conferência de Moscou realizada em agosto de 1987 e a Conferência das Nações Unidas para o Meio Ambiente e Desenvolvimento (CNUMAD) ou Rio92, realizada no Rio de Janeiro em $1992^{6}$.

No Brasil o marco legal da EA é a lei no 9.795, de 27 de abril de 1999 Lei de Educação Ambiental - a qual institui a Política Nacional de Educação Ambiental (PNUMA, BRASIL, 1999). A citada lei define a EA como sendo os processos por meio dos quais o indivíduo e a coletividade constroem valores sociais, conhecimentos, habilidades, atitudes e competências voltadas para a conservação do meio ambiente, bem de uso comum do povo, essencial à sadia qualidade de vida e a sua sustentabilidade (BRASIL, 1999).

Leff (2001) conceitua a Educação Ambiental com um meio fértil à mudança de comportamento e desenvolvimento do pensamento crítico.

A Educação Ambiental fomenta novas atitudes nos sujeitos sociais, e novos critérios de tomada de decisões dos governos, guiada pelos princípios de sustentabilidade ecológica e diversidade cultural, internalizando-os na racionalidade econômica e no planejamento do desenvolvimento. Isto implica em educar para formar um pensamento crítico, criativo e prospectivo, capaz de analisar as complexas relações entre processos naturais e sociais, para atuar no ambiente com uma perspectiva global, mas diferenciada pelas diversas condições naturais e culturais que o definem (LEFF, 2001, p.256).

O desafio dos educadores que adotam essa pedagogia é capacitar seus alunos com habilidades práticas, analíticas, filosóficas e éticas, despertar neles um sentido de admiração e respeito pela natureza para que possam redesenhar a presença humana neste mundo (MOUSINHO, 2003; ADAMS, 2007).

A Educação Ambiental provê conhecimentos e habilidades que possibilitam às pessoas capacidade para dialogar, questionar, mobilizar-se e participar ativamente da vida em comunidade, passando a intervir na gestão de uso dos recursos naturais e na tomada de decisões que afetam a qualidade de vida da população e do ambiente onde vivem (SILVA; GORAYEB, 2012). Por conseguinte, exerce o papel de contribuir para que as pessoas se apropriem de condutas responsáveis e conscientes no uso e interação com os recursos naturais no seu dia-a-dia (CUBA, 2011). Na concepção adotada por Ruiz (1994), contribui nao apenas para equilibrar desenvolvimento econômico e reduzir o avanço da degradação ambiental, como também para fortalecer

6 Ver capítulo 36 da Agenda 21.

Revbea, São Paulo, V. 11, № 4: 289-305, 2016. 
estruturas políticas. Nesse sentido é fundamental para o fortalecimento das estruturas de governança.

Os esforços de implementação da EA nas escolas do Semiárido podem ser classificados em quatro grupos:

i) Realização de projetos de Educação Ambiental - não interferem ou alteram a estrutura curricular ou nos conteúdos das disciplinas. Atuam por meio de ações extracurriculares as quais mobilizam alunos, professores e familiares com o objetivo de promover a consciência ambiental e estimular a participação social. Existe uma precária documentação de tais projetos, mas sabe-se que são muitos, apresentam várias semelhanças entre si e encontram-se disseminados por toda a região semiárida;

ii) Produção de material didático - a ausência de material didático com informações sobre a cultura, características econômicas, sociais e ambientais do Semiárido é colocada como um problema para a difusão da EA nas escolas locais. Nesse sentido, foram produzidos materiais como os livros "Conhecendo o Semi-Arido" volumes 1 e 2 (pela RESAB), o paradidático: Recomeço de Cantiga em Curaçá: Brincadeiras e histórias infantis (parceria do Instituto Regional de Pequena Agropecuária Apropriada - IRPAA, Fundação Abrinq/Programa Crer pra Ver e UNICEF), a série de desenhos Água, Vida e Alegria no Semiárido (pela ASA), a coletânea "Em cada Saber um Jeito de Ser. Educação de Jovens e Adultos no Semiárido Brasileiro" Módulos I e II; III e IV (SOUZA, 2013);

iii) Formação de professores: muitos professores não se sentem preparados para inserir questões relacionadas à Educação Ambiental em suas disciplinas. O aperfeiçoamento e a formação permanente de educadores está sendo implementado em várias escolas do Semiárido (ROCHA; MACHADO,2004);

iv) Alteração na estrutura curricular - A reorientação de propostas pedagógicas e reformas curriculares são complexas e demandam tempo e profissionais capacitados. No entanto, trata-se de uma condição para a concretização da EA e está previsto no artigo 26 da Lei de Diretrizes e Bases da Educação Nacional - LDB. O que se ensina na escola deve estar em sintonia com a realidade dos alunos. A RESAB vem desempenhando um importante papel na construção de um currículo contextualizado para o Semiárido (LIMA,2006).

Apesar dos esforços no sentido de implementar uma EA nas escolas do Semiárido, estas ainda atuam como agentes propagadores de um currículo pouco capaz de despertar o sentimento de protagonismo nas crianças e suas famílias, contribuindo para a formação de cidadãos conformados e inertes diante da realidade na qual encontram-se inseridos. Um exemplo característico desse comportamento é a ausência de disciplinas como EA na grade curricular. A importância dessa disciplina para a qualidade das escolas do Semiárido 
precisa ser reconhecida, uma vez que favorece a participação popular. Como relatado nos estudos de caso apresentados por Nachtigal (1982), apesar de ideias e recursos externos contribuírem para melhorar as escolas (especialmente, as rurais) um alto nível de participação local também é essencial para tal propósito.

\section{Educação Ambiental nas escolas dos municípios do Semiárido}

A convivência com o Semiárido, como fundamento de desenvolvimento sustentável da região, está centrada nos saberes e culturas da população local (ASA, 2010), os quais não se encontram nos livros didáticos geralmente adotados nas escolas da região, sejam elas públicas ou privadas, localizadas em áreas urbanas ou rurais. Contudo, ao contrário de eximir tais escolas de seu papel formador, essa configuração deve estimular as mudanças curriculares necessárias para a "educação popular" libertadora proposta por Josué de Castro, ainda em 1952, como forma de capacitar populações marginalizadas para o enfrentamento de seus problemas (CASTRO, 1984).

As mudanças curriculares na perspectiva da EA são esperadas há vários anos. Em 1991 o Ministério da Educação e Cultura (MEC), por meio da Portaria 678 resolveu que todos os currículos nos diversos níveis de ensino deveriam contemplar conteúdos de Educação Ambiental. A Política Nacional de Educação Ambiental, no Capítulo 2, Seção 2, Artigo 9, coloca que a EA na escola é aquela desenvolvida no âmbito dos currículos das instituições de ensino públicas e privadas, englobando: a educação básica, educação superior, educação especial, educação profissional e educação de jovens e jovens e adultos. Dispõe, ainda, que a Educação Ambiental não deve ser implantada como disciplina específica no currículo de ensino, o que pressupõe alterações nos conteúdos das disciplinas para além do "conhecimento do mundo físico e natural e da realidade social e política" (Art. $23, \S 1^{\circ}$, Lei de Diretrizes e Base, instituída pela Lei 9.394 de 30/1112/96). Assim, espera-se a presença do componente ambiental nos parâmetros curriculares nacionais (PCN). Contudo, como relata Souza $(2013$, p.2)

a escola no Semiárido pouco se preocupou com a produção de conhecimentos que criassem condições de a população superar a realidade que a envolve e as questões cotidianas que lhes são postas, inclusive pelas peculiaridades climático-ambientais presentes nessa região.

O cenário identificado por Souza (2013) diz respeito à realidade das escolas do Semiárido em geral, e é resultado de um contexto que integra um conjunto de fatores que limitam a inserção da Educação Ambiental de forma transversal nas disciplinas regulares do currículo das mesmas. 
Segundo Jacobi et al. (2003), os professores devem ser capazes de reelaborar as informações ambientais de modo a transmitir o seu significado e as suas interseções com os diferentes contextos vivenciados pelos alunos. No entanto, grande parte dos professores locais enfrentam dificuldades até mesmo na transmissão do conteúdo de suas disciplinas específicas e não se sentem preparados para tratar dos problemas ambientais na perspectiva transformadora requerida pela EA, a qual espera que os alunos recebam estímulos que levem à formação de valores, à definição de comportamentos e ao desenvolvimento de uma consciência crítica frente às questões ambientais locais (SORRENTINO, 1998). A carência de materiais didáticos e a falta de tempo para a preparação de aulas mais elaboradas também são citadas, de forma recorrente, como barreiras à implantação da EA nas escolas do Semiárido.

Barbosa e Santos (2015) a partir da análise de dezoito artigos sobre ações e práticas em EA desenvolvidas no Semiárido, entre 2005 e 2015, identificaram características regionais como o público envolvido, os locais onde são implantadas as ações, as temáticas abordadas e os recursos didáticos adotados. Segundo as autoras, as ações e práticas em Educação Ambiental ainda são timidamente divulgadas no Semiárido. Contudo, uma análise dos trabalhos publicados permite uma visão geral da região (Quadro 2).

Quadro 2: Características gerais da Educação Ambiental no Semiárido Brasileiro. Uma síntese a partir de publicações sobre o tema, no período 2005 a 2015.

\begin{tabular}{|l|l|}
\hline \multicolumn{1}{|c|}{ Característica } & \multicolumn{1}{|c|}{ Descrição } \\
\hline Público envolvido & $\begin{array}{l}\text { Alunos e professores são o principal público alvo das ações } \\
\text { e práticas em EA no Semiárido, enquanto demais } \\
\text { moradores, agricultores e gestores apresentam baixa } \\
\text { inserção. }\end{array}$ \\
\hline $\begin{array}{l}\text { Locais onde são implantadas as } \\
\text { ações e práticas em EA }\end{array}$ & $\begin{array}{l}\text { O ambiente escolar é o local onde, predominantemente, as } \\
\text { ações e práticas são implementadas. Embora menos } \\
\text { frequente, nota-se uma extensão no âmbito da relação } \\
\text { escola - comunidade. As escolas em questão abrangem } \\
\text { aquelas situadas em áreas rurais e urbanas. }\end{array}$ \\
\hline Temáticas abordadas & $\begin{array}{l}\text { Os temas mais comuns adotados para se trabalhar a EA no } \\
\text { Semiárido são: água e recursos hídricos, seguidos de } \\
\text { reciclagem/coleta seletiva, desmatamento, Bioma Caatinga e } \\
\text { Agroecologia/Agricultura Familiar. }\end{array}$ \\
\hline Recursos didáticos adotados & $\begin{array}{l}\text { Os principais recursos didáticos empregados são } \\
\text { Palestras/Seminários e Oficinas. Em menor escala surgem } \\
\text { as dinâmicas/jogos e ações de mobilização da comunidade. } \\
\text { Nota-se, no entanto, que é comum mesclar mais de um } \\
\text { recurso didático. }\end{array}$ \\
\hline
\end{tabular}

Fonte: Adaptado de Barbosa e Santos (2015)

Do ponto de vista do papel do Estado na implantação da EA, entende-se que no Semiárido a gestão municipal poderia dar uma contribuição significativa, haja vista que cape ao município a responsabilidade pelos ensinos infantil e fundamental. Assim, é relevante uma discussão sobre como o poder local 
como ente federado autônomo mais próximo da população se posiciona na promoção da EA na região, na perspectiva da adoção de mecanismos de gestão facilitadores da sua implementação nas escolas municipais.

As 1.133 prefeituras do Semiárido podem contribuir para a implementação da EA nas escolas municipais por meio de mecanismos de gestão da educação. Dentre estes, os principais são: Plano Municipal de Educação, Conselho Municipal de Educação, Fundo Municipal de Educação e a Inclusão da Modalidade Educação Ambiental no Plano Municipal de Educação. O Plano Municipal de Educação (PME) deve estar integrado à realidade do município e contemplar as necessidades educacionais dos cidadãos, o que transcende a oferta de vagas ou garantia da universalização do ensino. O PME deve definir focos e estabelecer as diretrizes e metas para a educação sendo, portanto, um documento orientador das ações a serem implementadas. No entanto, como pode-se notar por meio da Tabela 1, a sua presença é observada em apenas $61,3 \%$ dos municípios do Semiárido, apesar de se tratar de uma exigência prevista na Lei Federal oํ 10.172, de 9 de janeiro de 2001, que instituiu o Plano Nacional de Educação (PNE).

Tabela 1: Mecanismos de gestão municipal da educação nos municípios do Semiárido (Ano-base 2011).

\begin{tabular}{|c|c|c|c|c|c|c|}
\hline $\begin{array}{l}\text { Unidade da } \\
\text { Federação }\end{array}$ & $\begin{array}{l}\text { Total de } \\
\text { municípios } \\
\text { da } \\
\text { Unidade } \\
\text { da } \\
\text { Federação }\end{array}$ & $\begin{array}{c}\text { Número de } \\
\text { municípios } \\
\text { inseridos } \\
\text { no } \\
\text { Semiárido }\end{array}$ & $\begin{array}{l}\text { Existência } \\
\text { de Plano } \\
\text { Municipal } \\
\text { de } \\
\text { Educação }\end{array}$ & $\begin{array}{l}\text { Existência } \\
\text { de } \\
\text { Conselho } \\
\text { Municipal } \\
\text { de } \\
\text { Educação }\end{array}$ & $\begin{array}{l}\text { Existência } \\
\text { de Fundo } \\
\text { Municipal } \\
\text { de } \\
\text { Educação }\end{array}$ & $\begin{array}{l}\text { Existência de } \\
\text { Inclusão da } \\
\text { Modalidade } \\
\text { Educação } \\
\text { Ambiental no } \\
\text { Plano Municipal } \\
\text { de Educação }\end{array}$ \\
\hline Alagoas & 102 & 38 & 28,9 & 39,5 & 36,8 & 36,4 \\
\hline Bahia & 417 & 265 & 40,8 & 89,4 & 47,1 & 15,8 \\
\hline Ceará & 184 & 150 & 91,3 & 83,3 & 93,3 & 28,5 \\
\hline $\begin{array}{l}\text { Minas } \\
\text { Gerais }\end{array}$ & 853 & 85 & 88,2 & 81,2 & 51,8 & 5,3 \\
\hline Paraíba & 223 & 170 & 44,4 & 88,8 & 39,6 & 11,5 \\
\hline Pernambuco & 185 & 122 & 81,8 & 96,7 & 44,6 & 24,2 \\
\hline Piauí & 224 & 127 & 58,6 & 46,9 & 61,7 & 3,9 \\
\hline $\begin{array}{l}\text { Rio Grande } \\
\text { do Norte }\end{array}$ & 167 & 147 & 72,6 & 100,0 & 67,1 & 8,5 \\
\hline Sergipe & 75 & 29 & 27,6 & 86,2 & 55,2 & 25,0 \\
\hline $\begin{array}{l}\text { Semiárido } \\
\text { Brasileiro }\end{array}$ & - & 1.133 & 61,3 & 84,2 & 57,2 & 16,4 \\
\hline
\end{tabular}

Fonte: Elaborada a partir de IBGE (2011)- Pesquisa Perfil dos Municípios.

Os Conselhos Municipais de Educação (CME) são colegiados formados por representantes da comunidade escolar e da sociedade civil com o objetivo de decidir sobre as demandas educacionais do município. Caso este não possua PME, cabe ao CME o papel de inspirar, incentivar, cobrar e orientar todo o processo de elaboração, execução e avaliação do PME (MONLEVADE,

Revbea, São Paulo, V. 11, № 4: 289-305, 2016. 
2003). A partir dessas prerrogativas e considerando que se trata de um mecanismo de gestão mais comum que os PME, é factível admitir que os CME podem assumir papel determinante na condução de processos de implementação da EA nos municípios do Semiárido, demandando para isso o interesse da comunidade.

O processo de descentralização ocorrido após a promulgação da Constituição Federal de 1988, o qual atribuiu novas competências aos municípios e reduziu os recursos federais aplicados na educação (ROSAR, 1995). Nesse ambiente, o Fundo Municipal de Educação (FME) assume um caráter de provedor de recursos para que as prefeituras possam investir em ações voltadas para a educação no município. No entanto, poucos municípios $(57,2 \%)$ dispõem desse mecanismo para investir e melhorar a educação. As consequências esperadas são o agravamento das condições descritas por Farias (2009): precariedade das instalações escolares, desarticulação entre escola e comunidade, baixa capacitação de professores. Nesse contexto de carência a preocupação com a EA parece estar ausente da pauta de gestão municipal, dado que apenas 16,4\% dos 1.133 municípios do Semiárido incluem a modalidade Educação Ambiental em seu Plano Municipal de Educação.

A análise dos dados quantitativos apresentados na Tabela 1 pode ser complementada com a argumentação de Souza (2013) quando descreve os problemas de gestão da educação contextualizada no Semiárido destacando como questões preocupantes as condições de trabalho nos órgãos gestores (recursos físicos e humanos), a falta de estrutura para acompanhamento de alunos e professores, a necessidade de fortalecimento dos CMEs. A autora reflete, ainda, sobre a necessidade de mecanismos que garantam a formação de professores de modo a torná-los agentes propositivos e ativos no processo de inserção da educação contextualizada na escola.

Para Sauvé (1996) a concepção de educação e meio ambiente influencia e determina as escolhas em EA. Assim, abordagens diferenciadas de educação atribuem feições diferenciadas à EA na escola. A partir da tipologia de paradigmas educacionais proposta em Bertrand e Valois (1992), a autora argumenta que, em uma primeira abordagem, a EA tende a ser tratada de forma científica e tecnicista na abordagem educativa racional. $O$ professor assume a posição de autoridade e os alunos assumem o aprendizado por meio da memorização dos fatos e a relação homem-natureza é de dominação. Uma segunda abordagem, a educativa humanística, coloca 0 aluno e a aprendizagem como foco ressaltando a importância de integrar a dimensão afetiva nos programas de EA. A relação homem-natureza é de respeito e harmonia. A terceira abordagem, educativa inventiva, enfoca a relação simbiótica entre homem, natureza e sociedade. Essa terceira abordagem favorece a construção de uma visão crítica do conhecimento e de mudanças sociais, sendo a mais coerente com a proposta da EA e devendo ser, portanto, inspiração para as escolas do Semiárido. Ressalta-se, no entanto, que em qualquer das abordagens é a concepção do professor que influencia as opções pedagógicas (HART, 1990). 


\section{Considerações Finais}

A Educação Ambiental apresenta particularidades que a colocam como uma estratégia para o desenvolvimento sustentável do Semiárido brasileiro. Essa percepção já pode ser identificada em muitas das práticas de convivência com o Semiárido as quais são implementadas por instituições atuantes em nível governamental e não governamental. Essas práticas têm sido exitosas e refletem em sua essência o saber e a riqueza cultural da população local. No entanto, há muito a ser feito no âmbito da educação formal.

De um modo geral existe um ambiente desfavorável às mudanças necessárias à implementação da Educação Ambiental nas escolas, apesar da legislação pertinente. O governo municipal como ator mais próximo da população e responsável pelo seu bem estar, encontra-se omisso na implementação de mecanismos de gestão da educação o que agrava a condição de precariedade da escolas locais e tem desdobramentos que afetam a inserção da Educação Ambiental nos currículos escolares, dado que tais mecanismos poderiam ser catalisadores de processos de sensibilização da população, de formação de professores e, consequentemente, de transformação de comportamentos para enfrentar com os problemas socioeconômicos e ambientais da região. Por fim, entendemos que a Educação Ambiental institucionalizada como modalidade de ensino, é um meio consistente de construção do saber ambiental e de conscientização das pessoas, bem como de disseminação desta tomada de consciência a partir das gerações presentes e entre as futuras gerações.

\section{Referências}

ADAMS. B.G. O que é Educação Ambiental - Definições de Educação Ambiental. Disponível em:< http://www.apoema.com.br/geral.htm $>$. Acesso em: 24 nov. 2014.

ANDRADE. F.L..; QUEIROZ. P.V.M. Articulação no Semiárido Brasileiro - ASA e o seu Programa de Formação e Mobilização e para Convivência com o Semiárido: A Influência da ASA na Construção de Políticas Públicas. In: Políticas públicas para o Semiárido: experiências e conquistas no Nordeste do Brasil. Fortaleza: Fundação Konrad Adenauer, p. 26-53, 2009.

ARAÚJO, C.S.F.; SOUSA, A.N. Estudo do processo de desertificação na caatinga: uma proposta de Educação Ambiental. Ciência \& Educação. v. 17. n. 4. p. 975-986. 2011.

BAPTISTA, N.Q.; CAMPOS, C.H. Educação contextualizada para a convivência com o Semiárido. In: CONTI, I.L.; SCHROEDER, E.O. (organizadores). Convivência com o Semiárido Brasileiro: Autonomia e Protagonismo Social. / Fundação de Apoio da Universidade Federal do Rio Grande do Sul - FAURGS/REDEgenteSAN / Instituto Ambiental Brasil Sustentável - IABS / Agência Espanhola de Cooperação Internacional para 0 
Desenvolvimento - AECID / Ministério do Desenvolvimento Social e Combate a Fome - MDS / Editora IABS. Brasília-DF. Brasil - 2013.

BARBOSA, G.K.A.; SANTOS, E.M. Educação Ambiental no Semiárido: uma revisão sistemática das experiências e práticas. Ambiente \& EducaçãoRevista de Educação Ambiental, v. 20, n. 1, p. 66-86, 2015

BERTRAND. Y.; VALOIS. P. École et sociétés. Montréal: Éditions Agence d'Arc. 1992.

BRAGA, O.R. Educação e convivência com o semi-árido: introdução aos fundamentos do trabalho político-educativo no semi-árido brasileiro. In: KÜSTER, A.; MATTOS, B.H.O.M. (Orgs). Educação no contexto do semiárido brasileiro. Fortaleza: Fundação Konrad Adenauer, p. 25-44. 2004.

BRASIL. PRESIDÊNCIA DA REPÚBLICA. Lei no. 9.795, de 27 de abril de 1999. Dispõe sobre a Educação Ambiental. institui a Política Nacional de Educação Ambiental e dá outras providências. Diário oficial da República do Brasil. Brasília, DF: 27 de abr. de 1999.

BUAINAIN, A.M.; GARCIA JUNIOR, R. Desenvolvimento rural do semiárido brasileiro: transformações recentes. desafios e perspectivas ". Confins [Online]. Disponível em: http://confins.revues.org/8633. Acesso em 24 jan. 2015.

CASTRO, J. Geografia da fome. 0 dilema brasileiro: pão ou aço. 10 edição. Rio de Janeiro: Edições Antares. 1984.

CUBA, M.A. Educação Ambiental nas escolas. Educação, Cultura e Comunicação, v. 1, n. 2, p.23-31. 2011.

FARIAS, A.E.M.; PINHEIRO, J.N. Do combate à seca à convivência com o semiárido: (re) significando a política para os nordestes. In: Semiárido: estado. políticas públicas e saúde. p. 99 - 119. Coleção Mossoroense. Sobral: Edições Universitárias. 2012.

FARIAS, A.E.M. Educação contextualizada e a convivência com o semi-árido no assentamento Acauã-PB. Dissertação de Mestrado apresentada ao Programa de Pos-Graduacao em Historia. do Centro de Ciencias Humanas. Letras e Artes da Universidade Federal da Paraiba - UFP. 2009.

HART, P. Rethinking teacher education environmentally. In: ENGLESON, D.C.; DISINGER, J.F. (Eds.) Preparing Classroom teachers to beEnvironmental Educators. Monographs in Environmental Education and Environmental Studies. 7. Troy.Ohio: North American Association for Environmental Education.1990.

HUNGERFORD, H.R.; VOLK, T.L. Changing learner behavior through environmental education. The journal of environmental education. v. 21. n. 3. p. 8-21. 1990.

JACOBI, P.R. et al. Educação Ambiental. cidadania e sustentabilidade. Cadernos de pesquisa. v. 118. n. 3. p. 189-205. 2003. 
LEFF, E. Saber ambiental: sustentabilidade, racionalidade, complexidade, poder. Petrópolis: Vozes. 2001.

LIMA, E.S. Educação Contextualizada no Semi-árido: Construindo Caminhos para Formação de Sujeitos Críticos e Autônomos. 2006. 88f. Monografia (Especialização em Docência do Ensino Superior) Coordenação de Pósgraduação e Pesquisa da Faculdade Santo Agostinho. Teresina. 2006.

LIMA, P.V.P.S.; KHAN. A.S. Formação superior: uma prioridade da educação para a sustentabilidade no Brasil. In: Responsabilidade Social das Empresas: a Contribuição das Universidades. v. 10. São Paulo: Ed.Periópolis. Instituto Ethos. 2011.

LOPES, A.C. Os parâmetros curriculares nacionais para o ensino médio e a submissão ao mundo produtivo: o caso do conceito de contextualização. Educação \& Sociedade. v. 23. n. 80. p. 386-400. 2002.

MONLEVADE, J. A. A importância do Conselho Municipal de Educação na elaboração. implantação e acompanhamento da execução do Plano Municipal de Educação. In: BRASIL. Ministério da Educação. Secretaria de Educação Infantil e Fundamental. Caderno de referência pró-conselho. Brasília: Programa Nacional de Capacitação de Conselheiros Municipais de Educação Pró-Conselho. 2003. 48 p.

MOURA, A. Princípios e fundamentos de uma proposta educacional de apoio ao desenvolvimento sustentável. Recife: Bagaço. 2003.

MOUSINHO, P. Glossário. In: TRIGUEIRO. A. (Coord.). Meio ambiente no século 21. Rio de Janeiro: Sextante. 2003.

NACHTIGAL, P.M. Rural Education: In Search of a Better Way. Westview Press. Inc.. 5500 Central Ave.. Boulder. CO. 80301. 1982.

NOBRE. P. Mudanças climáticas e desertificação: os desafios para o Estado brasileiro. p. 25-35. In: Desertificação e mudanças climáticas no Semiárido Brasileiro. Campina Grande: Instituto Nacional do Semiárido - INSA. 2011. 209p.

PATON, D.; JOHNSTON, D. Disasters and communities: vulnerability. resilience and preparedness. Disaster Prevention and Management. v. 10. n. 4. p. 270-277. 2001.

RESAB - Rede de Educação do semiárido Brasileiro. Educação para a convivência com o Semiárido: reflexões teórico-práticas. Juazeiro. BA: Selo Editorial. 2006.

ROCHA, E.N.; MACHADO, J.C.P. Formação de educadores rurais: construindo uma política de Educação contextualizada. In: KÜSTER, A.; MATTOS, B.H.O.M. (Orgs). Educação no contexto do semiárido brasileiro. Fortaleza: Fundação Konrad Adenauer, p. 185-198. 2004. 
ROSAR, M.F.F. Globalização e descentralização: o processo de desconstrução do sistema educacional brasileiro pela via da municipalização. Campinas: Tese de Doutorado. UNICAMP. 1995.

RUIZ, J.R. Grass-roots education and the environmental dimension of development. Environmental Training. Newsletter of the Environmental Training Network for Latin America and the Caribbean. 5(11). 10-13. 1994.

SAUVÉ, L. Environmental education and sustainable development: a further appraisal. Canadian Journal of Environmental Education (CJEE). v. 1. n. 1. p. pp. 7-34. 1996.

SILVA, E.V.; GORAYEB, A. (Org.). Agroecologia e Educação Ambiental aplicadas ao desenvolvimento comunitário. Fortaleza: Expressão Gráfica e Editora. 2012.

SILVA, E.V.; RODRIGUEZ, J.M.M.; MEIRELES, A.J.A.. (orgs.). Planejamento ambiental e bacias hidrográficas (Tomo 1): Planejamento e gestão de bacias hidrográficas. Fortaleza: Edições UFC. 2011.

SILVA, R.M.A. Entre o combate à seca e a convivência com o semiárido: políticas públicas e transição paradigmática. Revista Econômica do Nordeste. Fortaleza. v. 38. n. 3. jul./set. 2007.

SORRENTINO, M. De Tbilisi a Tessaloniki. a Educação Ambiental no Brasil. In: JACOBI, P.R. et al. (orgs.). Educação. meio ambiente e cidadania: reflexões e experiências. São Paulo: SMA.1998. p.27-32.

SOUZA, I.P.F. A gestão da educação contextualizada no semiárido: questões para o debate. Cadernos de Estudos Sociais. v. 27. n. 1. p. 1-15. 2013.

VIANA, M.O.L; RODRIGUES, M.I.V. Um Índice Interdisciplinar de Propensão à Desertificação (IPD): Instrumento de Planejamento. Revista Econômica do Nordeste. Fortaleza. v. 30. n. 3 p. 264-294. jul.-set. 1999. 